\title{
Gudrun Guttenberger
}

Die Gottesvorstellung im Markusevangelium 


\title{
Beihefte zur Zeitschrift für die neutestamentliche Wissenschaft und die Kunde der älteren Kirche
}

\author{
Herausgegeben von \\ James D. G. Dunn - Carl A. Holladay \\ Hermann Lichtenberger · Jens Schröter \\ Gregory E. Sterling · Michael Wolter
}

Band 123

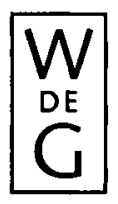

Walter de Gruyter - Berlin · New York 


\section{Gudrun Guttenberger}

\section{Die Gottesvorstellung im Markusevangelium}

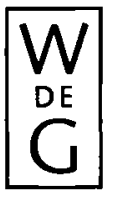

Walter de Gruyter - Berlin · New York 
(0) Gedruckt auf säurefreiem Papier, das die US-ANSI-Norm über Haltbarkeit erfüllt.

ISBN 3-11-018129-0

\section{Bibliografische Information Der Deutschen Bibliothek}

Die Deutsche Bibliothek verzeichnet diese Publikation in der Deutschen Nationalbibliografie; detaillierte bibliografische Daten sind im Internet über http://dnb.ddb.de abrufbar.

(C) Copyright 2004 by Walter de Gruyter GmbH \& Co. KG, 10785 Berlin Dieses Werk einschließlich aller seiner Teile ist urheberrechtlich geschützt. Jede Verwertung außerhalb der engen Grenzen des Urheberrechtsgesetzes ist ohne Zustimmung des Verlages unzulässig und strafbar. Das gilt insbesondere für Vervielfältigungen, Übersetzungen, Mikroverfilmungen und die Einspeicherung und Verarbeitung in elektronischen Systemen.

Printed in Germany

Einbandgestaltung: Christopher Schneider, Berlin 